\title{
Genetic Influences on Level and Stability of Self-Esteem
}

\author{
MICHELLE B. NEISS \\ CONSTANTINE SEDIKIDES \\ JIM STEVENSON \\ University of Southampton, Southampton, UK
}

\begin{abstract}
We attempted to clarify the relation between self-esteem level (high vs. low) and perceived self-esteem stability (within-person variability) by using a behavioral genetics approach. We tested whether the same or independent genetic and environmental influences impact on level and stability. Adolescent twin siblings $(n=183$ pairs) completed level and stability scales at two time points. Heritability for both was substantial. The remaining variance in each was attributable to nonshared environmental influences. Shared environmental influences were not significant. Level and stability of self-esteem shared common antecedents via genetic and non-shared environmental influences. Nonetheless, stability was influenced by substantial unique genetic and non-shared environmental influences. The results validate the notion that level and stability are partially autonomous components of self-esteem.
\end{abstract}

In the last two decades alone, thousands of studies have focused on the correlates, causes, and consequences of self-esteem. Professionals and academics alike have been fascinated by it, and so have statespersons and legislators. The Task Force on Self-Esteem and Personal and Social Responsibility, the National Council for Self-Esteem, and the National Association of Self-Esteem are all testimony to a "culture of self-worth" (Twenge \& Campbell, 2001, p. 325). For reviews see: Baumeister, Campbell, Krueger, \& Vohs, 2003; Crocker \& Park, 2004; Sedikides \& Gregg, 2003.

Research on self-esteem, however, has rarely taken advantage of behavioral genetics methodologies to illuminate substantive research questions. Recently, there has been a move towards greater integration of social and biological levels of analysis (Berntson \& Cacioppo, 2000; Klein, Rozendal, \& Cosmides, 2002; Plomin, DeFries, McClearn, \& McGuffin, 2001). In that spirit, the present investigation complements past research by focusing on genetic and environmental influences on self-esteem. Genetically informative designs help differentiate genetic from environmental influences on self-esteem, thus increasing our understanding of underlying processes. In particular, we address the distinction between two key components of self-esteem: level and stability.

Received 17 June 2004; accepted 27 October 2005

We thank Elizabeth Gramzow for her valuable help with data collection.

Correspondence should be addressed to: Michelle Neiss, Department of Behavioral Neurosciences, CR 131, Oregon Health \& Science University, Portland, OR 97239-3098, USA. E-mail: neissm@ohsu.edu 


\section{Self-Esteem Level and Self-Esteem Stability}

Self-esteem level reflects the extent to which an individual likes or values the self. High self-esteem is linked with positive outcomes such as increased subjective wellbeing (DeNeve \& Cooper, 1998; Diener \& Diener, 1995), decreased emotional distress (i.e., anxiety, depression, and loneliness: Jones, Freemon, \& Goswick, 1981; Sedikides, Rudich, Gregg, Kumashiro, \& Rusbult, 2004; Tennen \& Herzberger, 1987), successful coping with stressors (Bednar, Wells, \& Peterson, 1989; Greenberg et al., 1992), task persistence (Di Paula \& Campbell, 2002; McFarlin, Baumeister, \& Blascovich, 1984), and healthier life styles (Abernathy, Massad, \& Romano-Dwyer, 1995; Vohs, Bardone, Joiner, Abramson, \& Heatherton, 1999). It is not surprising, then, that there is a concern both with ways to raise self-esteem level, particularly among children and adolescents (Mecca, Smelser, \& Vasconcellos, 1989; National Association for Self-Esteem, 2000), and with understanding the etiology of selfesteem level (Crocker \& Wolfe, 2001; Leary \& Baumeister, 2000; Pyszczynski, Greenberg, Solomon, Arndt, \& Schimel, 2004).

Self-esteem stability is typically defined as within-person variability in self-esteem assessments, or "the magnitude of short-term fluctuations in individuals' contextually based current self-esteem" (Kernis et al., 1998, p. 658). This will be referred to as statistical stability. Kernis and his colleagues (Kernis, Grannemann, \& Barclay, 1989, 1992; Kernis et al., 1998) pioneered the assessment of statistical stability by measuring current self-esteem repeatedly over a period of several days or weeks and using the standard deviation $(S D)$ within each individual as an index of stability. Statistical stability is a critical predictor of psychological outcomes. Compared to their stable self-esteem counterparts, unstable self-esteem individuals have unclear self-concepts while showing less self-determination in goal regulation (Kernis, Paradise, Whitaker, Wheatman, \& Goldman, 2000), focus on threatening aspects of unpleasant interpersonal events while manifesting a self-protective (less masteryoriented) attitude toward learning (Waschull \& Kernis, 1996), and report a higher frequency of depressive symptoms when faced with daily hassles while overgeneralizing the negative implications of domain-specific failure (Kernis et al., 1998).

\section{Level and Stability as Distinct Components of Self-Esteem}

Importantly, level and statistical stability may be linked to distinct psychological functions. Hostility proneness is better understood as a function of unstable and high self-esteem (Kernis et al., 1989), and positive affectivity is better understood as a function of stable and high self-esteem (Kernis et al., 2000), rather than simply a function of high self-esteem in either case. Also, although a strong concurrent relation exists between low self-esteem level and depression (Tennen \& Herzberger, 1987), this relation does not necessarily imply that low self-esteem constitutes a vulnerability factor for the onset of depression (Barnett \& Gotlib, 1988). Indeed, the suggestion that self-esteem is lower in subsequently depressed (compared to normal) persons has received mixed support (Hokanson, Rubert, Welker, Hollander, \& Hedeen, 1989; Lewinsohn, Steinmetz, Larson, \& Franklin, 1981). Instead, selfesteem instability is a better predictor of depression proneness than level of selfesteem in the presence of stressful life events or daily hassles (Butler, Hokanson, \& Flynn, 1994; Kernis et al., 1998). For example, academic failure predicts depressive symptomatology only among individuals with unstable self-esteem (Roberts \& Monroe, 1992). 
For the purposes of the present investigation, however, we focused on perceived rather than statistical stability. Measures of perceived stability do have an established history in the field (e.g., Rosenberg's, 1965, Stability of Self scale). Perceived stability correlates considerably higher with self-esteem level than statistical stability (Kernis et al., 1989, 1992). More importantly, perceived stability correlates negatively and more strongly than statistical stability with indices of selfconcept vulnerability or maladjustment such as social anxiety, overgeneralization, fear of negative evaluation, self-validation, self-handicapping, and impersonal orientation (Kernis et al., 1992). If the distinction between level and perceived stability is important, what is the intrapersonal basis of the differences between these components? We speculate that level is associated with self-relevant emotions (e.g., pride and shame; Brown \& Marshall, 2001), whereas perceived stability is linked to a general psychopathology cluster (Kernis et al., 1992).

It is likely, then, that level and perceived stability are partially autonomous components of self-esteem. Nonetheless, the exact nature of their relation may have been overlooked in the endeavor to differentiate between them. Recent empirical reports have drawn attention to the substantial overlap between various psychological constructs (Judge, Erez, Bono, \& Thoresen, 2002; Watson, Suls, \& Haig, 2002), such as self-esteem, negative affect, and neuroticism. In questioning the unique contribution of closely related traits, these empirical reports highlight potential problems arising from the creation of ever-finer distinctions among and within psychological constructs. Within this context, it is important to consider carefully the overlap between level and perceived stability. Prior research suggests that higher levels of self-esteem are associated with higher perceived stability (De Cremer \& Sedikides, 2005; Kernis et al., 1989, 1992). Is the overlap between the two constructs more compelling than their uniqueness? Does the addition of perceived stability allow a better understanding of self-esteem than level alone? Such concerns call for more detailed consideration of the relation between these two self-esteem components.

We used a multivariate behavioral genetics analysis to identify the genetic and environmental pathways linking level and perceived stability of self-esteem as well as those unique to perceived stability. This approach may further our understanding of the unique etiology of perceived stability, thus complementing research on the construct's unique correlates. Differing predictions concerning the pattern of common and unique genetic architecture that underlie level and perceived stability help to illustrate the potential contribution of our approach.

If the phenotypic differences in self-esteem level and perceived stability signify their reliance on partially different psychological systems, this would likely be reflected in the two components being subject to partially different genetic and environmental influences. Alternatively, any genetic influences on the two components may be carried through a common pathway. Such would be the case if genetic influences on a particular dimension of temperament explained the genetic influence in both level and perceived stability. For example, neuroticism is inversely related to level of self-esteem (Hills \& Argyle, 2001; Roberts, Kassel, \& Gotlib, 1995) and related to greater self-esteem instability (Roberts et al., 1995). Neuroticism is itself heritable (Jang, Livesley, \& Vernon, 1996; Loehlin, McCrae, Costa, \& John, 1998), thus possibly accounting for genetic influences on self-esteem level and perceived stability. Past research indicates that self-esteem level shows a genetic correlation with neuroticism (Roberts \& Kendler, 1999), although we lack evidence of a similar link with perceived stability. If a shared underlying temperament 
dimension explained entirely genetic influences on level and perceived stability, we would expect genetic influence on both to be carried by a common genetic factor.

Although the above description focuses on common genetic influence, a behavioral genetics analysis can also identify the extent to which environmental factors influencing level and perceived stability of self-esteem are common to both. In short, the pattern of genetic and environmental factors underlying the relation between the two self-esteem components can inform research on ways in which the components overlap and ways in which they are distinct.

\section{A Behavioral Genetics Analysis of Self-Esteem Level and Perceived Stability}

Although studies investigating the magnitude of genetic and environmental influences on self-esteem level are relatively scarce, the emerging pattern is that sibling similarity in self-esteem level is subject to genetic influences (Neiss, Sedikides, \& Stevenson, 2002). In adults, heritability estimates for self-esteem level range from $32-40 \%$, with the remaining variance attributable to non-shared environmental influences (Kendler, Gardner, \& Prescott, 1998; Roy, Neale, \& Kendler, 1995). The large magnitude of nonshared environment suggests that the unique environments that people experience account for the majority of between-person variation in levels of self-esteem.

In adolescents, the evidence concerning genetic influence on self-esteem level is somewhat mixed. Heritability estimates are at $60 \%$ in mid-adolescence, but nonsignificant in early adolescence (McGuire, Manke, Saudino, Reiss, Hetherington, \& Plomin, 1999). In children, the evidence is also mixed. Mother and teacher reports yield heritability estimates greater than $60 \%$, but children's own reports do not always show significant genetic influences (Neiderhiser \& McGuire, 1994). It is unclear whether the disparate heritability estimates result from developmental changes in the magnitude of genetic influence or from the small sample sizes in some of the research. In addition, the literature has two notable weaknesses. First, selfesteem has typically been the secondary rather than primary research focus. Second, the typical assessment method has involved non-standardized inventories. The first objective of the current investigation was to provide a rigorous test of the hypothesis that self-esteem level is genetically influenced.

Only two studies have assessed whether change or stability in self-esteem is attributable to genetic factors, shared environmental factors, or non-shared environmental influences. Longitudinal studies involving adolescents (McGuire et al., 1999) and children (Neiderhiser \& McGuire, 1994) found that genetic influences largely accounted for phenotypic stability. Non-shared environmental influences explained change in self-esteem over time. However, these studies assessed long-term trait stability rather than the predilection to experience frequent fluctuations in current or immediate feelings of self-worth. The second and more important objective of the present investigation was to find out if perceived selfesteem stability (operationalized as experiential frequency of short-term fluctuations in self-esteem) is genetically influenced. To that effect, we used a repeated measures design to strengthen confidence in the genetic and environmental estimates obtained. We assessed level and perceived stability twice across a three-month interval.

Finally, we wished to move beyond identifying the extent of genetic and environmental influences on self-esteem level and perceived stability at the univariate level. Identifying genetic and environmental factors underlying the relation between 
the two contributes additional information on how they are distinct. Thus, the third and most important objective of the investigation was to examine whether the two self-esteem components are subject to different genetic influences.

\section{Method}

\section{Participants}

Participants were drawn from the Register of Child Twins, a volunteer sample of twins in the United Kingdom (Eley, Lichtenstein, \& Stevenson, 1999). We asked twin pairs between the ages of 10 and 19 to complete independently questionnaires assessing how they felt about themselves. Participants completed the questionnaires at two time points, three months apart. Responses from 369 participants yielded data for 183 complete pairs: 54 monozygotic (MZ) female pairs; $24 \mathrm{MZ}$ male pairs; 38 dizygotic (DZ) female pairs; 29 DZ male pairs; and 38 DZ mixed-sex pairs. In this analysis, we use only those pairs in which both individuals completed the questionnaires at both time points.

\section{Measures}

Self-esteem level. We assessed self-esteem level using the 10-item Rosenberg SelfEsteem Inventory (RSI; Rosenberg, 1965). Participants stated their agreement with each item on a 4-point rating scale. Higher values indicate higher self-esteem level. Internal consistency for the scale was $\alpha=.86$ at Time 1 and $\alpha=.88$ at Time 2 .

Perceived self-esteem stability. We assessed perceived self-esteem stability using the 5-item Labile Self-Esteem Scale (LSES; Dykman, 1998). The scale measures the extent to which self-esteem fluctuates, and includes items such as: "How I feel about myself stays pretty much the same from day-to-day" and "I'm often feeling good about myself one minute, and down on myself the next minute" (reverse scored). Participants stated how true each statement was for them on a 5-point rating scale. Higher values indicate greater self-esteem stability. Internal consistency for the scale was $\alpha=.83$ at Time 1 and $\alpha=.86$ at Time 2 .

The criterion validity of the LSES is good, as this scale correlates with a standard self-esteem level scale (i.e., the RSI) at $r=.55, p<.001$ (De Cremer \& Sedikides, 2005), a pattern consistent with correlations reported not only by Kernis and colleagues (Kernis, Brown, \& Brody, 2000; Kernis \& Waschull, 1995) but also other researchers (Roberts et al., 1995) who used the SD. Additionally, the LSES correlates with other indices of the more general psychological construct of selfuncertainty, such as the self-doubt scale (Oleson, Poehlmann, Yost, Lynch, \& Arkin, 2000) and the self-concept clarity (Campbell, Trapnell, Heine, Katz, Lavallee, \& Lehman, 1996). Specifically, the LSES (i.e., higher perceived instability) correlates with the self-doubt scale at $r=.52, p<.001$, and with the self-concept clarity scale at $r=.75, p<.001$ (De Cremer \& Sedikides, 2005). ${ }^{1}$

\section{Data Analyses}

We used a behavioral genetics analysis to decompose the variance in self-esteem level and perceived stability across both times of measurement. A behavioral genetics approach apportions the observed differences between people (phenotypic variance) 
into subcomponents: shared environment, non-shared environment, and genetic. Total phenotypic or observed variance is the sum of the shared environmental variance, genetic variance, non-shared environmental variance, and measurement error.

The twin design estimates the variation in observed traits that can be ascribed to genetic influences by comparing the similarity between $\mathrm{MZ}$ twins and DZ twins (Neale \& Cardon, 1992). MZ twins share all genes that vary between individuals, whereas DZ twins share, on average, half of those genes. In the current study, all twins were reared together. Because the twin pairs share the same family, they are assumed to be influenced equally by those environmental influences that increase similarity among siblings (equal-environment assumption). Given that siblings are equally influenced by shared environment, if $\mathrm{MZ}$ twins are more alike than DZ twins, this pattern can be attributed to their greater genetic resemblance, thus providing evidence for heritable influences. If, however, the MZ twins are no more similar than the DZ twins, there is no evidence for heritable influences on the trait. Rather, twin resemblance can be ascribed to shared environmental influences. Nonshared environmental influences are those environmental factors that serve to make twins different from each other. Non-shared environment estimates also include measurement error.

In a multivariate analysis, similar logic is extended to the overall pattern of relations among variables. Genetic influences affecting multiple variables in common are implicated when the MZ cross-correlation (the correlation between one twin's score on a variable with the other twin's score on a second variable) is greater than the DZ cross-correlation. We used two forms of multivariate genetic analysis. The first was a bivariate Cholesky analysis, which identified the extent to which the genetic and environmental influences on one measure (i.e., level) also influence a second characteristic (i.e., stability) at any one time point. The second is a common pathway model, which examines in more detail the origins of shared genetic and environmental influences both between measures and between time points.

\section{Results}

First, we examined phenotypic relations. Because individuals in twin pairs are not sampled independently, we used the PROC MIXED procedure in SAS 9.1 (SAS Institute Inc.) to adjust the standard errors using the Huber/White sandwich estimator (Maas \& Hox, 2004). Level and perceived stability were related significantly at both time one $(\beta=.27, p<.001)$ and time two $(\beta=.26, p<.001)$, indicating that people with higher level also reported greater stability. This pattern is consistent with past research (De Cremer \& Sedikides, 2005; Kernis et al., 2000; Kernis \& Waschull, 1995; Roberts et al., 1995). Further, levels were significantly correlated across the two time points $(\beta=.73, p<.001)$. Also, perceived stability correlated significantly across time $(\beta=.56, p<.001)$.

Age was not significantly related to level or perceived stability. However, the two variables differed by gender. Males reported higher levels $\left(t_{\text {time } 1}=-3.04, p<.01\right.$; $\left.t_{\text {time } 2}=-2.82, \quad p<.01\right) \quad$ and greater stability $\left(t_{\text {time } 1}=-3.75, \quad p<.001\right.$; $\left.t_{\text {time } 2}=-3.25, p<.01\right)$ at both time points. Age and gender effects may artificially inflate estimates of twin similarity. We did not have theoretical reasons to believe that the magnitude of genetic or environmental influences would differ across the age range of the participants, nor did our design have the statistical power to test for gender differences in the magnitude of genetic or environmental influences. The 
standard appropriate solution in this case is to regress out the effects of age and gender. Therefore, we used residualized scores controlling for both age and gender in all subsequent analyses.

\section{Behavioral Genetics Analyses}

Because our sample included both same-sex and mixed-sex DZ pairs, we investigated whether sibling resemblance differed across these two groups. To examine gender differences in sibling similarity, we used regression analyses predicting sibling ${ }_{1}$ 's values on each variable from sibling, ${ }_{2}$ s value, type of DZ twin pair, and a sibling ${ }_{2} \times$ type of twin pair interaction term. Sibling resemblance did not interact with sibling type: Same-sex DZ twin pairs were no more alike than mixed-sex DZ pairs in level or perceived stability. We therefore combined all DZ twin pairs in the analyses.

Table 1 displays the twin correlations and descriptive information for level and perceived stability. The cross-twin correlations, both within and between traits, are demarcated by dotted lines. The cross-twin correlations within traits are highlighted by the solid boxes within the dotted lines. The MZ twins showed a somewhat greater resemblance in both level and perceived stability as compared to the DZ twins. This pattern signifies genetic influences for both level and perceived stability. In addition, the cross-correlations (e.g., Level_Twin 1 with Stability_Twin 2) were also higher among MZ twins, suggesting common genetic influences underlying both self-esteem components. We estimated the genetic and environmental influences on self-esteem with structural equation models, analyzed with the Mx program (Neale, 2002). We tested first bivariate Cholesky models, in order to assess the relation between level and perceived stability within each time point. These analyses guided the final model, which examined simultaneously genetic and environmental influences on the two self-esteem components at both time points.

Figure 1 depicts the bivariate Cholesky behavioral genetics model. The Cholesky model estimates genetic and environmental influences common to both variables and additional genetic and environmental influences specific to perceived stability. Our models included additive genetic influences $\left(\mathrm{a}^{2}\right)$, shared environment $\left(\mathrm{c}^{2}\right)$, and nonshared environmental influences $\left(\mathrm{e}^{2}\right)$. The genetic factors (A) were correlated between siblings, a correlation of 1.0 for $\mathrm{MZ}$ twins and .5 for DZ twins, representing the degree of genetic relatedness. The shared environmental factors (C) were correlated perfectly between all siblings. The non-shared environmental factors (E) were uncorrelated between siblings.

A Cholesky decomposition is a standard model for bivariate behavioral genetics analyses (Neale \& Cardon, 1992). Alternative models may have more parameters (for example, specific genetic and environmental components on all variables), but can run the risk of over-factorization in the bivariate case. The Cholesky decomposition suited our research questions well: It modeled directly the relation between level and perceived stability and also allowed for estimation of any remaining genetic or environmental influences on perceived stability. The common genetic and environmental paths to self-esteem level (see paths $\mathrm{a}_{11}, \mathrm{c}_{11}$, and $\mathrm{e}_{11}$ in Figure 1) estimated total genetic and environmental effects for this variable. The common genetic and environmental paths to perceived stability $\left(\mathrm{a}_{1 \mathrm{~s}}, \mathrm{c}_{1 \mathrm{~s}}, \mathrm{e}_{1 \mathrm{~s}}\right.$ ) decomposed the correlation between level and perceived stability into three components: genetic, shared-environment, and non-shared environment. The specific paths to stability $\left(\mathrm{a}_{2 \mathrm{~s}}, \mathrm{c}_{2 \mathrm{~s}}, \mathrm{e}_{2 \mathrm{~s}}\right)$ estimated those genetic and environmental effects that influence perceived stability alone, separate from level. The combined 


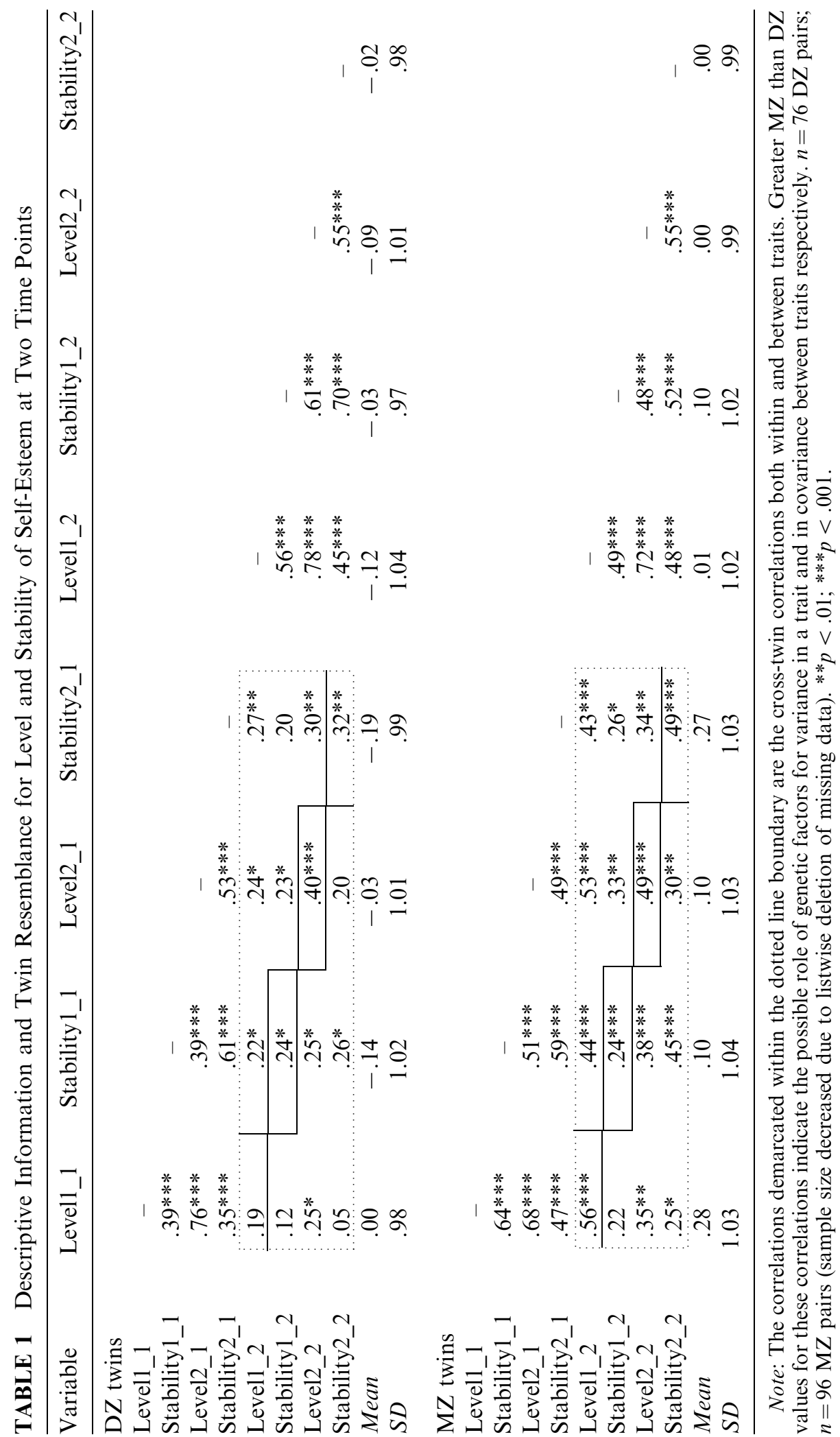




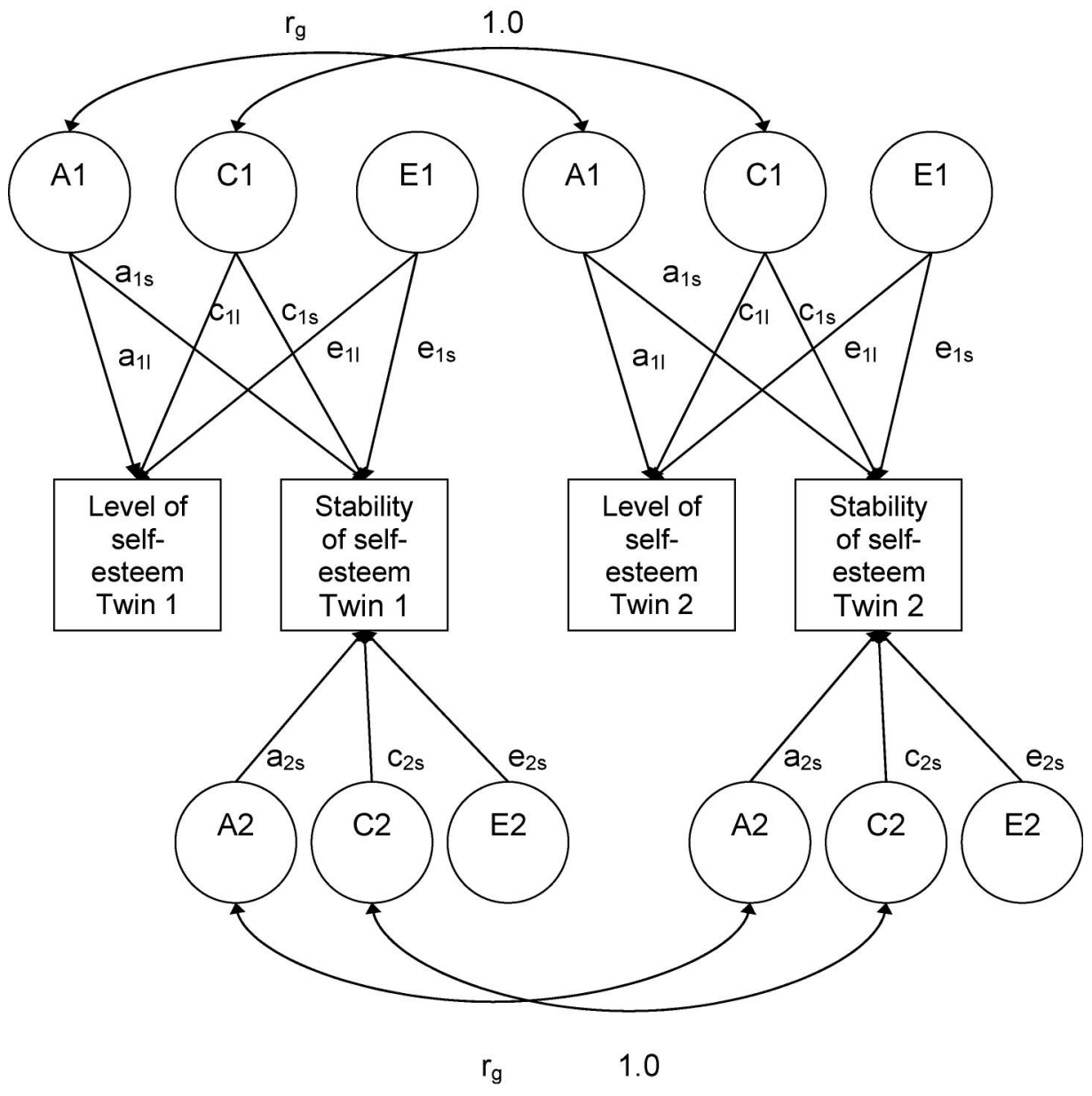

FIGURE 1 Cholesky decomposition of the relation between level and stability of self-esteem within one time point. Notes: $\mathrm{a}=$ additive genetic influences; $\mathrm{c}=$ shared environmental influences; $\mathrm{e}=$ non-shared environmental influences. $r_{\mathrm{g}}=$ genetic correlation; 1.0 for $\mathrm{MZ}$ twins, .5 for $\mathrm{DZ}$ twins.

effects of the common and specific paths to perceived stability allowed calculation of total genetic and environmental influences on this variable.

Time 1 bivariate Cholesky model. The Cholesky ACE model fits the data well, as evidenced through a non-significant chi-square value, $\chi^{2}(11, N=172)=15.12$. Although the Root Mean Squared Error Approximations (RMSEA) value of .067 fell above the recommended cut-off value of .06 (Hu \& Bentler, 1999), the chi-square test provides a more stringent criteria of model fit. The first four columns of numbers in Table 2 present the path estimates and total genetic and environmental effects for this model. The first column represents the common genetic and environmental paths to both level and perceived stability. Squaring the path estimates to level yields the portion of variance in level accounted for genetic and environmental factors. As can be seen in the third column, genetic influences on self-esteem level were substantial 
M. B. Neiss et al.

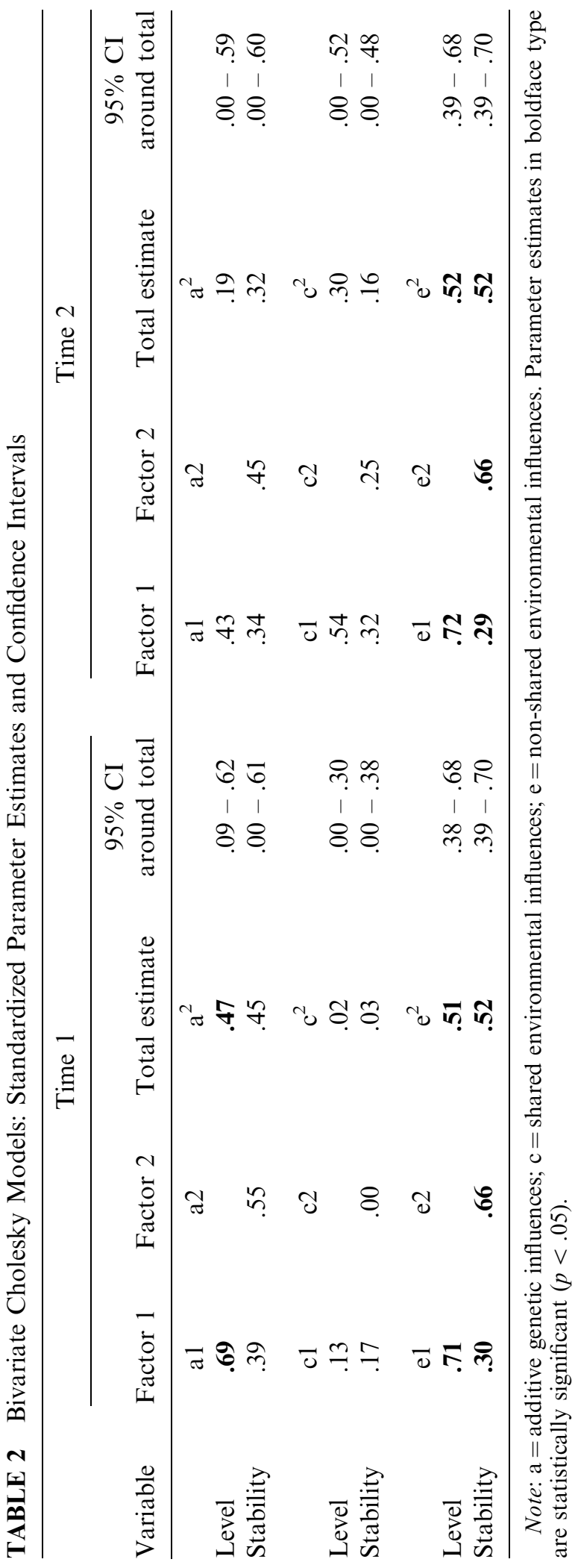


$(47 \%)$, whereas shared environmental influences were minimal $(2 \%)$. Non-shared environmental influences were also substantial (51\%).

The genetic and environmental effects on perceived stability are broken down into those effects common to level (Factor 1) and those effects specific to perceived stability (Factor 2). Perceived stability demonstrated common genetic, shared environmental, and non-shared environmental influences with level. All shared environmental effects were held in common with level. Specific genetic and specific non-shared environmental paths were larger, however, than the common paths. Stated differently, perceived stability showed moderate distinct genetic and nonshared environmental influences.

Total genetic and environmental estimates are calculated by summing the squared paths for each effect (Factors 1 and 2). For example, for perceived stability the total genetic influence is $.39^{2}+.55^{2}=.45$. Again, both genetic $(45 \%)$ and non-shared environmental $(52 \%)$ influences were substantial, whereas shared environmental effects were minimal $(3 \%)$.

Time 2 bivariate Cholesky model. The Cholesky ACE model fits the data well at time 2 also, as evidenced through a non-significant chi-square value, $\chi^{2}$ (11, $N=172)=2.28$, $n s$, and low RMSEA (.000). The final four columns in Table 2 present the path estimates and total genetic and environmental effects for the Cholesky model at time 2. Again, separate columns represent the common genetic and environmental paths (Factor 1) and the specific genetic and environmental paths (Factor 2). Genetic influences on self-esteem at time 2 were modest (19\%) whereas shared environmental influences were larger $(30 \%)$. Once again, non-shared environmental influences were substantial (52\%). As in the previous analysis, perceived stability demonstrated common genetic and environmental influences with level alongside substantial specific genetic and environmental influences.

Common pathway model. The previous analyses left open two important questions. First, do the common genetic and environmental influences arise because level and perceived stability are indices of a unidimensional and overarching self-esteem factor? Second, are the somewhat different estimates of genetic and environmental influences across the two time points meaningful? In order to address these questions, we simultaneously modeled genetic and environmental influences on self-esteem level and perceived stability across both time points using a common pathway model. The purpose of this analysis was to probe the presence of a higher order common factor for level and perceived stability and the importance of cross-time fluctuations.

In the full common pathway model, both level and perceived stability load on one higher order self-esteem factor. The common genetic and environmental effects on level and perceived stability operate through this higher order factor. Specific genetic and specific environmental effects influence directly the observed phenotypes. This model allowed us to test whether level and perceived stability can be seen as indices of one superordinate construct. Fit estimates are displayed in Table 3. This model

TABLE 3 Model Fitting Results: Common Pathway Model

\begin{tabular}{lcccccc}
\hline Model & $\chi^{2}$ & $d f$ & $p$ & AIC & RMSEA & $\Delta \chi^{2}$ \\
\hline Full common pathway & 124.12 & 54 & .000 & 16.12 & .110 & - \\
Constrained common pathway & 127.52 & 62 & .000 & 3.52 & .094 & $3.40, n s$ \\
\hline
\end{tabular}


yielded a poor fit, as evidenced by a significant chi-square, $\chi^{2}(54, N=172)=124.12$, $p<.001$, and a high RMSEA of .110 .

We then applied a set of constraints to examine the statistical significance of the observed differences in magnitude of genetic and shared environmental influences between time 1 and time 2 . We constrained the factor loadings from the higher order factor to level at both time points to be equal, and the loading to perceived stability at both time points to be equal. We also constrained the corresponding specific paths to level at both time points to be equal, and the specific paths to perceived stability at both time points to be equal. This model, the constrained common factor model, still indicates that level and stability operate through one higher-order factor. However, it also adds the constraint that cross-time differences in either construct are relatively insubstantial.

The constrained common factor model also showed somewhat poor fit, $\chi^{2}$ $(62, N=172)=127.52, p<.001$; RMSEA of .094. However, the Akaike's Information Criterion (AIC) for this model was lower than that of the full model (3.52 vs. 16.12), and the chi-square was not significantly different. The AIC indicates that the chisquare value is just about equal to two times the degrees of freedom. Furthermore, the constrained model is more parsimonious, indicating that the model is better overall. These results suggest that the differences between time 1 and time 2 reflect sampling variance rather than meaningful change across time. Figure 2 provides an illustration of the constrained model and the accompanying standardized path estimates. (Confidence intervals for the estimated path coefficients are provided in Table 4.)

Despite a significant chi-square value, the constrained model warranted further interpretation in light of the overall fit, given the sample size and the equality constraints that we applied. As can be seen in this model, genetic influences on the latent self-esteem factor were substantial $(.74 \times .74=55 \%)$, shared environmental influences were modest $(9 \%)$, and non-shared environmental influences were also substantial $(36 \%)$. Level loaded more strongly on latent self-esteem than did perceived stability.

The results disconfirm the notion that level and perceived stability of self-esteem represent simply indices of one common factor. The lack of absolute fit can be seen as evidence that despite sharing a common genetic and environmental structure, the two variables do not index well a higher-order latent factor. Inspection of the specific genetic and environmental effects reveals additional support for the distinctiveness of level and perceived stability, evidenced by a moderate genetic effect specific to stability. This effect was statistically significant (see Table 4 for the confidence intervals around the estimates), suggesting that perceived stability of self-esteem was influenced by additional genetic influence (e.g., $23 \%$ of the variance in perceived stability) after modeling the common genetic influences on both level and perceived stability. Selfesteem level, however, showed no evidence of specific genetic or shared environmental influences. Specific non-shared environmental influences accounted for significant variance in both level and perceived stability. These specific non-shared environmental effects also included measurement error for each component of self-esteem.

\section{Discussion}

The current study examined the relation between self-esteem level and perceived stability using both phenotypic and behavioral genetics analyses. The results highlighted the importance of genetic and non-shared environmental influences for explaining variance in level and perceived stability of self-esteem as well as the covariance between the two components. The findings underscored commonalities 


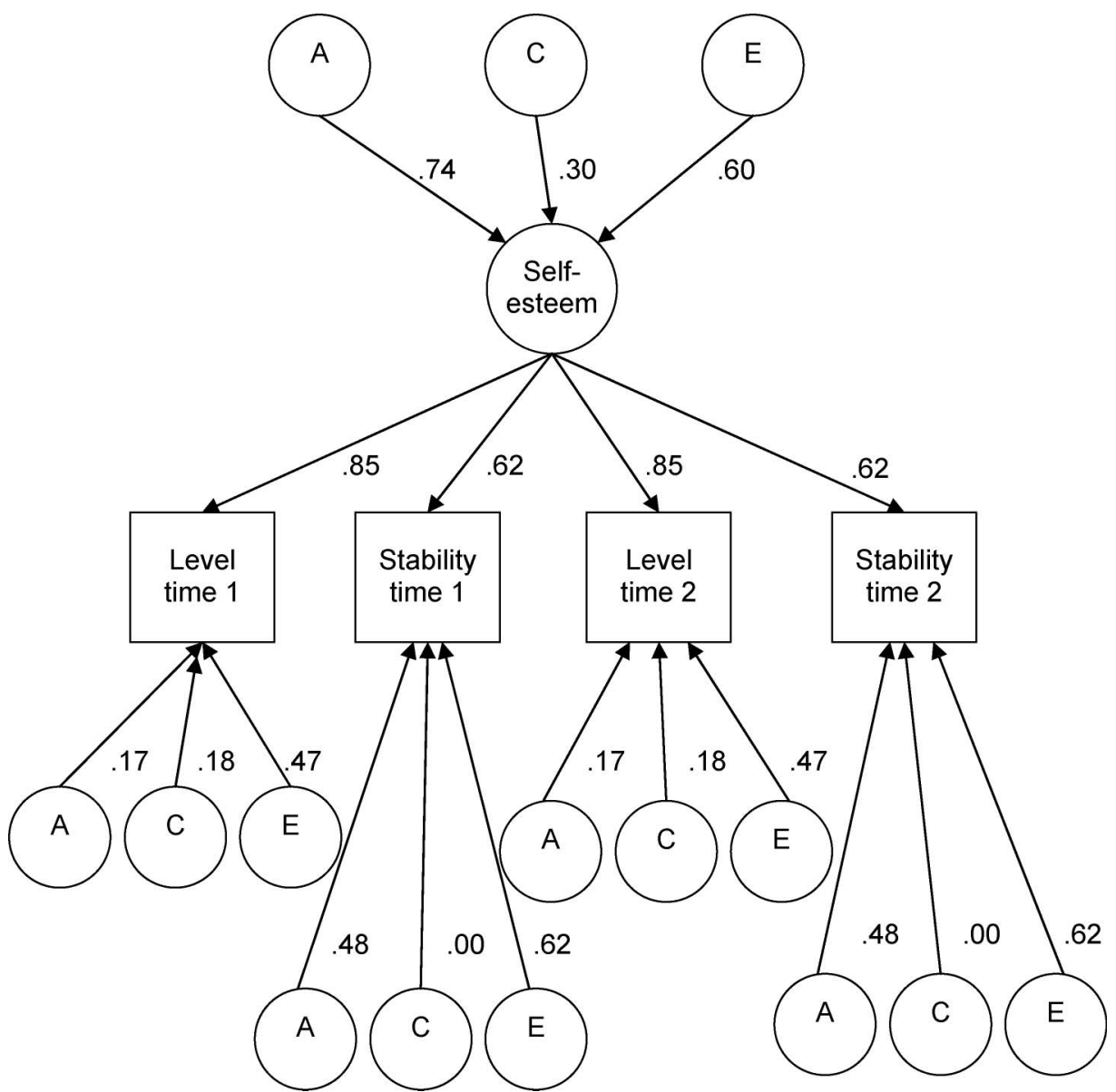

FIGURE 2 Genetic and environmental influences on level and stability of selfesteem over time using common pathway model with equality constraints for paths at time 1 and time 2. Note: $\mathrm{A}=$ additive genetic influences; $\mathrm{C}=$ shared environmental influences; $\mathrm{E}=$ non-shared environmental influences.

between the variables, while also shedding light on what is unique about perceived stability.

\section{Phenotypic Analyses}

We began by investigating the phenotypic relation between self-esteem level and perceived stability. Participants with higher levels of self-esteem reported greater stability of self-esteem. This pattern of results is consistent with previous research. For example, Kernis et al. (1989) obtained a correlation of .62 between level and perceived stability, Kernis et al. (1992) reported a correlation of .58 between these two constructs, and De Cremer and Sedikides (2005) obtained a correlation of .55. The phenotypic relation between level and perceived stability is consistent with the finding that individuals with lower self-esteem are less certain about their opinion of themselves (Campbell, 1990; Kernis et al., 2000). Additionally, the correlation between level and perceived stability reaffirms the need to identify the common 
TABLE 4 Confidence Intervals around Path Estimates from Constrained Common Pathway Model

\begin{tabular}{|c|c|c|c|c|c|c|}
\hline \multirow[b]{2}{*}{ Parameter } & \multicolumn{2}{|c|}{$\begin{array}{c}\text { Latent } \\
\text { self-esteem factor }\end{array}$} & \multicolumn{2}{|c|}{$\begin{array}{c}\text { Level of } \\
\text { self-esteem }\end{array}$} & \multicolumn{2}{|c|}{$\begin{array}{l}\text { Stability of } \\
\text { self-esteem }\end{array}$} \\
\hline & Estimate & $95 \% \mathrm{CI}$ & Estimate & $95 \% \mathrm{CI}$ & Estimate & $95 \% \mathrm{CI}$ \\
\hline Common gen. & .74 & $.20-.88$ & & & & \\
\hline Common sh. env. & .30 & $.00-.70$ & & & & \\
\hline Common non. env. & .60 & $.48-.74$ & & & & \\
\hline Specific gen. & & & .17 & $.00-.35$ & .48 & $.06-.57$ \\
\hline Specific sh. env. & & & .18 & $.00-.32$ & .00 & $.00-.42$ \\
\hline Specific non. env. & & & .47 & $.41-.55$ & .62 & $.55-.69$ \\
\hline
\end{tabular}

Note: gen. = genetic; sh. env. = shared environment; non. env. $=$ non-shared environment.

antecedents of each. Our behavioral genetics analyses explored this latter concern further, by providing an analysis of the genetic and environmental architecture underlying the two variables.

\section{Behavioral Genetics Analyses}

We examined genetic and environmental contributions to between-person differences in both self-esteem level and perceived stability, as well as genetic and environmental contributions to the relation between the two. We assessed each variable twice. A series of analyses pointed to moderate genetic influences on both level and perceived stability, minimal shared environmental influences, and substantial non-shared environmental influences. This pattern suggests that genetic influences explain sibling similarity in level and perceived stability, whereas environmental effects make siblings different from one another.

Overall, the current research bolsters the notion that self-esteem level among preadolescents and adolescents is genetically influenced. Previous studies of adolescents and children have reported rather mixed findings concerning the magnitude of genetic influences on level, with estimates at some time points being non-significant (McGuire et al., 1999; Neiderhiser \& McGuire, 1994). However, our common pathway model demonstrated that genetic influences were significant in explaining individual differences in both level and perceived stability at both time points.

Additionally, the current analyses speak to the relation between self-esteem level and perceived stability. Consistent with the partial independence view, we observed some overlap between these two self-esteem components. The genetic and environmental influences common to both components were noteworthy in the bivariate analyses within each time point. Furthermore, our final model illustrated that significant genetic and non-shared environmental influences act on both level and perceived stability through one common superordinate factor. Taken together, these results add to growing awareness of the commonalities underlying many psychological constructs (Judge et al., 2002; Watson et al., 2002).

Although our results help identify the overlap between self-esteem level and perceived stability via both genetic and non-shared environmental pathways, the findings also point to the meaningful uniqueness of perceived stability. The majority of both the genetic and the non-shared environmental influences on perceived stability were specific 
to this variable. In other words, perceived self-esteem stability was influenced by some genetic and non-shared environmental factors that were distinct from those that influenced self-esteem level. This finding is consistent with the notion that perceived stability partially reflects a different psychological core than level. Furthermore, the substantial unique genetic influence suggests that the unique effects on perceived stability reflect more than just measurement error or "crud" (Meehl, 1990).

We cannot rule out the possibility that what is unique to perceived self-esteem stability is the broader construct of within-person instability or variability. In other words, we might obtain similar results if we looked at the relation between selfesteem level and instability in negative affect, for example. Future research will need to validate that perceived instability in self-esteem is meaningfully different from affective instability (e.g., neuroticism). Research on whether statistical instability in self-esteem is separable from affective instability is somewhat mixed. Gable and Nezlek (1998) report that multiple measures of statistical instability, including selfesteem, anxiety and control, loaded on one latent instability factor. They did not report full fit results for their models, however, and the tested models primarily reflected a goal of differentiating level and stability. They did not test explicitly whether self-esteem instability and affective instability (anxiety) were separable. Other studies show that self-esteem instability has different effects on anger and hostility (Kernis et al., 1989) or anxiety and depression (Roberts \& Gotlib, 1997) than does affective instability. Nevertheless, the distinction between self-esteem instability and affective instability remains to be validated for measures of statistical instability as well.

The presence of moderate genetic influences on both level and perceived stability of self-esteem does not imply that either is genetically predetermined. Our results highlight in particular the relevance of non-shared environmental influences. It is the unique environmental effects that individuals experience, not those shared with their siblings, which have the greatest impact on both level and perceived stability. These unique environmental influences contribute to differences rather than similarities between siblings. Differential sibling experiences may be one measurable non-shared environmental factor to explore in future research. For example, Plomin, Manke, and Pike (1996) found that adolescents' self-esteem level was related to perceptions of their parents' parenting style. Specifically, within a family, the sibling with higher self-esteem reported more positive and less negative parenting. The extent to which certain parenting practices affect both self-esteem level and perceived stability is less clear. Research by Kernis, Brown, and Brody (2000) reveals a complex pattern of results. Some parenting behaviors, such as expressed criticism, are related to both lower level and greater statistical instability of self-esteem. In other cases, interactions between level and stability reveal that children with stable high selfesteem perceive their parents more positively. Our results suggest that some nonshared environmental effects influence both level and stability, but the majority of non-shared environmental effects on perceived stability were unique. The modest common non-shared environment may reflect shared error variance.

One potential limitation of our approach is that twin studies have less power to detect shared environmental influences than other behavioral genetics designs. In addition, one of the assumptions of our model is that both types of twins are subject to shared environmental influences to the same degree (the equal-environment assumption). We did not test this assumption directly. It is plausible that MZ twins experience more homogenous environments than do DZ twins. For example, perhaps the parents of $\mathrm{MZ}$ twins emphasize their similarities rather than differences 
to a greater extent. Nevertheless, it is worth noting that direct tests of the equalenvironment assumption generally support its validity (Plomin et al., 2001).

Despite this limitation, we detected some shared environmental effects at time 2, primarily because the DZ twins showed comparatively stronger resemblance to one another at the second assessment. The shared environmental estimates did not reach significance, however. Our findings converge with those from studies of both adopted children (McGue, Sharma, \& Benson, 1996; Neiderhiser \& McGuire, 1994) and other types of siblings (McGuire et al., 1999). Multiple studies using different samples and methodology have also found that shared environmental influences have little to no impact on self-esteem level. Thus, studies reporting significant impact of family structure (Bynum \& Durm, 1996; McCormick \& Kennedy, 2000) or parenting style (Lamborn, Mounts, Steinberg, \& Dornbusch, 1991) without having controlled for the genetic similarity between family members may be misleading. If these aspects of the family do have an effect, it is more likely that they result in differences rather than similarities between family members and hence contribute to non-shared environmental estimates. A particular parenting style may be important, but may enhance the self-esteem of some children and not their siblings. Stated somewhat differently, the fit between child temperament and parental behavior may affect children's self-esteem (Eder \& Mangelsdorf, 1997).

\section{Future Research Directions}

Given that this study presents the first behavioral genetics analyses of the relation between self-esteem level and perceived stability, it is perhaps premature to speculate about possible mechanisms of the genetic correlation underlying the two. Certainly, the quantitative genetic approach used in the current study cannot directly identify specific genes that influence level or perceived stability. Such an analysis would require molecular genetic approaches (Plomin, Defries, Craig, \& McGuffin, 2003). Furthermore, genes will not code directly for self-esteem. A possible pathway for genetic influence on level and perceived stability may be through temperament. Neuroticism may be one candidate for such a route, although empirical evidence for a genetic correlation between neuroticism and perceived stability has yet to be established. Selfesteem level shares common genetic influences with neuroticism (Roberts \& Kendler, 1999) and broad negative affectivity (Neiss, Stevenson, Sedikides, Kumashiro, Finkel, \& Rusbult, 2005). It may well be that genetic influences on both level and perceived stability of self-esteem can be explained by genetic influences on neuroticism. Perceived stability of self-esteem may also share variance with other genetically-influenced traits, such as depression, separable from the shared variance with self-esteem level. Future studies could explore explicitly the role of neuroticism in explaining the genetic correlation between self-esteem level and perceived stability. In addition, future research could identify other mechanisms underlying both the common genetic and specific genetic factors uncovered in this study.

Also, further research will need to test the replicability of our findings with different assessments of level (e.g., observer ratings, implicit measures) and stability (e.g., observer ratings, standard deviation of scores on current self-esteem measures as introduced by Kernis and his colleagues, i.e., Kernis et al., 1989). In addition, future research agenda would need to examine directly whether the non-overlap between the two constructs is, at least in part, due to them being empirically anchored to different aspects of the affective system-self-esteem level being associated with self-conscious emotions (e.g., pride and shame) and self-esteem 
stability being linked with psychopathology. Finally, future research would need to replicate our findings with larger and more representative samples. Regardless, the study of self-esteem level and stability has a promising future.

\section{Conclusion}

Our study documented genetic influences on both level and perceived stability of selfesteem. The common genetic and non-shared environmental effects influencing the two variables were noteworthy, although perceived stability was influenced by specific genetic and non-shared environmental factors as well. These findings provide a balanced picture, conveying information on a possible common core underlying the two self-esteem components and information on how stability is unique. Attention to both sides of this issue will strengthen our understanding of self-esteem.

\section{Note}

1. This correlation between the LSES scale and self-concept clarity may be artificially inflated because the self-concept clarity scale contained items pertaining to short-term fluctuations in one's self-concept.

\section{References}

Abernathy, T. J., Massad, L., \& Romano-Dwyer, L. (1995). The relationship between smoking and self-esteem. Adolescence, 30, 899-907.

Barnett, P. A., \& Gotlib, I. H. (1988). Psychological functioning and depression: Distinguishing among antecedents, concomitants, and consequences. Psychological Bulletin, 104, 97-126.

Baumeister, R. F., Campbell, J. D., Krueger, J. I., \& Vohs, K. D. (2003). Does high self-esteem cause better performance, interpersonal success, happiness, or healthier lifestyles? Psychological Science in the Public Interest, 4, 1-44.

Bednar, R. L., Wells, M. G., \& Peterson, S. R. (1989). Self-esteem: Paradoxes and innovations in clinical theory and practice. Washington, DC: American Psychological Association.

Berntson, G. G., \& Cacioppo, J. T. (2000). Psychobiology and social psychology: Past, present, and future. Personality and Social Psychology Review, 4, 3-15.

Brown, J. D., \& Marshall, M. A. (2001). Self-esteem and emotion: Some thoughts about feelings. Personality and Social Psychology Bulletin, 27, 575-584.

Butler, A. C., Hokanson, J. E., \& Flynn, H. A. (1994). A comparison of self-esteem lability and low trait self-esteem as vulnerability factors for depression. Journal of Personality and Social Psychology, 66, 166-177.

Bynum, M. K., \& Durm, M. W. (1996). Children of divorce and its effect on their self-esteem. Psychological Reports, 79, 447-450.

Campbell, J. D. (1990). Self-esteem and clarity of the self-concept. Journal of Personality and Social Psychology, 59, 538-549.

Campbell, J. D., Trapnell, P. D., Heine, S. J., Katz, I. M., Lavallee, L. F., \& Lehman, D. R. (1996). Self-concept clarity: Measurement, personality correlates, and cultural boundaries. Journal of Personality and Social Psychology, 70, 141-156.

Crocker, J., \& Park, L. E. (2004). The costly pursuit of self-esteem. Psychological Bulletin, 130, $392-414$

Crocker, J., \& Wolfe, C. T. (2001). Contingencies of self-worth. Psychological Review, 108, $593-623$.

De Cremer, D., \& Sedikides, C. (2005). Self-uncertainty and responsiveness to procedural information. Journal of Experimental Social Psychology, 41, 157-173. 
DeNeve, K., \& Cooper, H. (1998). The happy personality: A meta-analysis of 137 personality traits and subjective well-being. Psychological Bulletin, 124, 197-229.

Di Paula, A., \& Campbell, J. D. (2002). Self-esteem and persistence in the face of failure. Journal of Personality and Social Psychology, 83, 711-724.

Diener, E., \& Diener, M. (1995). Cross-cultural correlates of life satisfaction and self-esteem. Journal of Personality and Social Psychology, 68, 653-663.

Dykman, B. J. (1998). Integrating cognitive and motivational factors in depression: Initial tests of a goal-orientation approach. Journal of Personality and Social Psychology, 74, $139-158$.

Eder, R. A., \& Mangelsdorf, S. C. (1997). The emotional basis of early personality development: Implications for the emergent self-concept. In R. Hogan, J. Johnson, \& S. Briggs (Eds.), Handbook of personality psychology (pp. 209-240). San Diego, CA: Academic Press.

Eley, T. C., Lichtenstein, P., \& Stevenson, J. (1999). Sex differences in the etiology of aggressive and non-aggressive antisocial behaviour: Results from two twin studies. Child Development, 70, 155-168.

Gable, S. L., \& Nezlek, J. B. (1998). Level and instability of day-to-day psychological wellbeing and risk for depression. Journal of Personality and Social Psychology, 74, 129-138.

Greenberg, J., Solomon, S., Pyszczynski, T., Rosenblatt, A., Burling, J., Lyon, D. et al. (1992). Why do people need self-esteem? Converging evidence that self-esteem serves an anxietybuffering function. Journal of Personality and Social Psychology, 63, 913-922.

Hills, P., \& Argyle, M. (2001). Emotional stability as a major dimension of happiness. Personality and Individual Differences, 31, 1357-1364.

Hokanson, J. E., Rubert, M. P., Welker, R. A., Hollander, G. R., \& Hedeen, C. (1989). Interpersonal concomitants and antecedents of depression among college students. Journal of Abnormal Psychology, 98, 209-217.

Hu, L., \& Bentler, P. M. (1999). Cutoff criteria for fit indexes in covariance structure analysis: Conventional criteria versus new alternatives. Structural Equation Modeling, 6, 1-55.

Jang, K. L., Livesley, W. J., \& Vernon, P. A. (1996). Heritability of the Big Five personality dimensions and their facets: A twin study. Journal of Personality, 64, 577-591.

Jones, W. H., Freemon, J. E., \& Goswick, R. A. (1981). The persistence of loneliness: Self and other determinants. Journal of Personality, 49, $27-48$.

Judge, T. A., Erez, A., Bono, J. E., \& Thoresen, C. J. (2002). Are measures of self-esteem, neuroticism, locus of control, and generalized self-efficacy indicators of a common core construct? Journal of Personality and Social Psychology, 83, 693-710.

Kendler, K. S., Gardner, C. O., \& Prescott, C. A. (1998). A population-based twin study of self-esteem and gender. Psychological Medicine, 28, 1403-1409.

Kernis, M. H., Brown, A. C., \& Brody, G. H. (2000). Fragile self-esteem in children and its associations with perceived patterns of parent-child communication. Journal of Personality, 68, 225-252.

Kernis, M. H., Grannemann, B. D., \& Barclay, L. C. (1989). Stability and level of self-esteem as predictors of anger arousal and hostility. Journal of Personality and Social Psychology, $56,1013-1022$.

Kernis, M. H., Grannemann, B. D., \& Barclay, L. C. (1992). Stability of self-esteem: Assessment, correlates, and excuse making. Journal of Personality, 60, 621-644.

Kernis, M. H., Paradise, A. W., Whitaker, D. J., Wheatman, S. R., \& Goldman, B. N. (2000). Master of one's psychological domain? Not likely if one's self-esteem is unstable. Personality and Social Psychology Bulletin, 26, 1297-1305.

Kernis, M. H., \& Waschull, S. B. (1995). The interactive roles of stability and level of selfesteem: Research and theory. In M. P. Zanna (Ed.), Advances in experimental social psychology (Vol. 27, pp. 93 -141). San Diego, CA: Academic Press.

Kernis, M. H., Whisenhunt, C. R., Waschull, S. B., Greenier, K. D., Berry, A. J., Herlocker, C. E. et al. (1998). Multiple facets of self-esteem and their relations to depressive symptoms. Personality and Social Psychology Bulletin, 24, 657-668. 
Klein, S. B., Rozendal, K., \& Cosmides, L. (2002). A social-cognitive neuroscience analysis of the self. Social Cognition, 20, 105-135.

Lamborn, S. D., Mounts, N. S., Steinberg, L., \& Dornbusch, S. M. (1991). Patterns of competence and adjustment among adolescents from authoritative, authoritarian, indulgent, and neglectful families. Child Development, 62, $1049-1065$.

Leary, M. R., \& Baumeister, R. F. (2000). The nature and functions of self-esteem: Sociometer theory. In M. P. Zanna (Ed.), Advances in experimental social psychology, (Vol. 32, pp. 1-62). New York: Academic Press.

Lewinsohn, P. M., Steinmetz, J. L., Larson, D. W., \& Franklin, J. (1981). Depression-related cognitions: Antecedent or consequence? Journal of Abnormal Psychology, 90, $213-$ 219.

Loehlin, J. C., McCrae, R. R., Costa, P. T., Jr., \& John, O. P. (1998). Heritabilities of common and measure-specific components of the Big Five personality factors. Journal of Research in Personality, 32, $431-453$.

Maas, C. J. M., \& Hox, J. J. (2004). The influence of violations of assumptions on multilevel parameter estimates and their standard errors. Computational Statistics and Data Analysis, 46, 427-440.

McCormick, C. B., \& Kennedy, J. H. (2000). Father-child separation, retrospective and current views of attachment relationship with father, and self-esteem in late adolescence. Psychological Reports, 86, 827-834.

McFarlin, D. B., Baumeister, R. F., \& Blascovich, J. (1984). On knowing when to quit: Task failure, self-esteem, advice, and nonproductive persistence. Journal of Personality, 52, $138-155$.

McGue, M., Sharma, A., \& Benson, P. (1996). The effect of common rearing on adolescent adjustment: Evidence from a US adoption cohort. Developmental Psychology, 32, $604-613$.

McGuire, S., Manke, B., Saudino, K. J., Reiss, D., Hetherington, M. E., \& Plomin, R. (1999). Perceived competence and self-worth during adolescence: A longitudinal behavioral genetic study. Child Development, 70, 1283-1296.

Mecca, A. M., Smelser, N. J., \& Vasconcellos, J. (1989). The social importance of self-esteem. Berkeley, CA: University of California Press.

Meehl, P. E. (1990). Why summaries of research on psychological theories are often uninterpretable. Psychological Reports, 66, 195-244.

National Association for Self-Esteem. (2000). Masters coalition-a work in progress. (Retrieved 4 July 2003 from: http://www.self-esteem-nase.org/masters.shtml)

Neale, M. C. (2002). Windows Mx GUI (Version 1.52a). [Computer software]. Retrieved from http://www.vcu.edu/mx/executables.html

Neale, M. C., \& Cardon, L. (1992). Methodology for genetic studies of twins and families. Norwell, MA: Kluwer.

Neiderhiser, J. M., \& McGuire, S. (1994). Competence during middle childhood. In J. C. DeFries, R. Plomin, \& D. W. Fulker (Eds.), Nature and nurture during middle childhood, (pp. 141 -151). Malden, MA: Blackwell.

Neiss, M. B., Sedikides, C., \& Stevenson, J. (2002). Self-esteem: A behavioural genetics perspective. European Journal of Personality, 16, 1-17.

Neiss, M. B., Stevenson, J., Sedikides, C., Kumashiro, M., Finkel, E. J., \& Rusbult, C. E. (2005). Executive self, self-esteem, and negative affectivity: Relations at the phenotypic and genotypic level. Journal of Personality and Social Psychology, 89, 593-606.

Oleson, K. C., Poehlmann, K. M., Yost, J. H., Lynch, M. E., \& Arkin, R. M. (2000). Subjective overachievement: Individual differences in self-doubt and concern with performance. Journal of Personality, 68, 491-524.

Plomin, R., Defries, J. C., Craig, I. W., \& McGuffin, P. (2003). Behavioral genetics in the postgenomic era. Washington, DC: APA Books.

Plomin, R., DeFries, J. C., McClearn, G. E., \& McGuffin, P. (2001). Behavioral genetics (4th ed.). New York: Worth Publishers. 
Plomin, R., Manke, B., \& Pike, A. (1996). Siblings, behavioral genetics, and competence. In G. H. Brody (Ed.), Sibling relationships: Their causes and consequences (pp. 75-104). Stamford, CT: Ablex.

Pyszczynski, T., Greenberg, J., Solomon, S., Arndt, J., \& Schimel, J. (2004). Why do people need self-esteem? A theoretical and empirical review. Psychological Bulletin, 130, $435-468$.

Roberts, J. E., Kassel, J. D., \& Gotlib, I. H. (1995). Level and stability of self-esteem as predictors of depressive symptoms. Personality and Individual Differences, 19, 217-224.

Roberts, S. B., \& Kendler, K. S. (1999). Neuroticism and self-esteem as indices of the vulnerability to major depression in women. Psychological Medicine, 29, 1101-1109.

Roberts, J. E., \& Monroe, S. M. (1992). Vulnerable self-esteem and depressive symptoms: Prospective findings comparing three alternative conceptualizations. Journal of Personality and Social Psychology, 62, 804-812.

Rosenberg, M. (1965). Society and the adolescent self-image, Princeton, NJ: Princeton University Press.

Roy, M., Neale, M. C., \& Kendler, K. S. (1995). The genetic epidemiology of self-esteem. British Journal of Psychiatry, 166, 813-820.

Sedikides, C., \& Gregg. A. P. (2003). Portraits of the self. In M. A. Hogg \& J. Cooper (Eds.), Sage handbook of social psychology (pp. 110-138). London: Sage Publications.

Sedikides, C., Rudich, E. A., Gregg, A. P., Kumashiro, M., \& Rusbult, C. (2004). Are normal narcissists psychologically healthy? Self-esteem matters. Journal of Personality and Social Psychology, 87, 400-416.

Tennen, H., \& Herzberger, S. (1987). Depression, self-esteem, and the absence of selfprotective attributional biases. Journal of Personality and Social Psychology, 52, 72-80.

Twenge, J. M., \& Campbell, W. K. (2001). Age and birth cohort differences in self-esteem: A cross-temporal meta-analysis. Personality and Social Psychology Review, 5, 321-344.

Vohs, K. D., Bardone, A. M., Joiner, T. E., Abramson, L. Y., \& Heatherton, T. F. (1999). Perfectionism, perceived weight status, and self-esteem interact to predict bulimic symptoms: A model of bulimic symptom development. Journal of Abnormal Psychology, $108,695-700$.

Waschull, S. B., \& Kernis, M. H. (1996). Level and stability of self-esteem as predictors of children's intrinsic motivation and reasons for anger. Personality and Social Psychology Bulletin, 22, 4-13.

Watson, D., Suls, J., \& Haig, J. (2002). Global self-esteem in relation to structural models of personality and affectivity. Journal of Personality and Social Psychology, 83, 185-197. 